\title{
Transparência Tributária Internacional: Um cerco aos paraísos fiscais
}

\section{International Tax Transparency: A siege on tax havens}

\author{
Eugênio Pacceli de Morais Bomtempo ${ }^{1 *}$, Marcos Aurélio Pereria Valadão ${ }^{2}$
}

\begin{abstract}
RESUMO
Esta pesquisa toma como objetivo examinar o desenvolvimento do comércio eletrônico no âmbito dos negócios globais e os novos riscos advindos de maior redução ou evasão do pagamento de impostos por "paraísos fiscais" na concorrência tributária internacional ; examina a questão da transparência fiscal, proteção de dados, a segurança das nações. Esta pesquisa qualitativa realizou-se por consultas bibliográficas; tomou como hipótese ser imprescindível ampliar a adesão das nações ao acordo internacional de transparência tributária formulado no âmbito da OCDE-G20. Percebeu-se que a corrosão da arrecadação tributária causa graves prejuízos sociais nos países em desenvolvimento. As convenções modelo contra a dupla tributação não resolvem a erosão das bases tributárias. A Lei Geral de Proteção de Dados protege os dados sensíveis dos cidadãos, mas não prejudica a transparência diante de relevante o interesse público. Uma nova ética civilizacional transparente precisa ser construída, em defesa da sustentabilidade das políticas públicas nas democracias ocidentais. Trata-se de um breve estudo estratégico considerando a frenética evolução tecnológica no cenário global, o que contribui para a formulação de políticas públicas mais realistas e eficazes. Eventual inanição tributária pode colocar em risco as democracias..
\end{abstract}

Palavras-chave: Globalização; E-commerce; Tributação internacional; Transparência fiscal.

\begin{abstract}
This research aims to examine the development of electronic commerce in the scope of global businesses and the new risks arising from greater reduction or evasion of tax payments by "tax havens" in international tax competition; examines the issue of fiscal transparency, data protection, the security of nations. This qualitative research was carried out through bibliographic consultations; took the hypothesis that it is essential to expand the adhesion of nations to the international tax transparency agreement formulated in the scope of the OECD-G20. It is noticed that the corrosion of tax collection causes serious social damage in developing countries. Model conventions against double taxation do not resolve the erosion of tax bases. The General Data Protection Law protects citizens' sensitive data, but does not impair transparency in the face of relevant public interest. A new transparent civilizational ethics needs to be built, in defense of the sustainability of public policies in Western democracies. This is a brief strategic study considering the
\end{abstract}

\footnotetext{
${ }^{1}$ Doutorando, Centro Universitário de Brasília - UNICEUB.

* E-mail: eugenio.bomtempo@gmail.com

${ }^{2}$ Professor na EPPG, Fundação Getúlio Vargas, Brasília- DF.
} 
frantic technological evolution in the global scenario, which contributes to the formulation of more realistic and effective public policies. Eventual tax starvation can put democracies at risk.

Keywords: Globalization; E-commerce; International taxation; Tax transparency.

\section{INTRODUÇÃO}

A Internet movimenta imensa quantidade de informações integrando os mercados internacionais, com isso, observa-se frenético crescimento do e-commerce, a baixo custo de instalação, o que abre novas oportunidades para o florescimento do comércio internacional. Novas tecnologias digitais, criptomoedas, transações por paraísos fiscais virtuais, a falta de transparência fiscal, são ocorrências que comprometem a arrecadação tributária e a saúde financeira de muitas nações. Esta realidade oferece desafios à proteção dos direitos humanos garantidos pelos Estados nacionais, um tanto fragilizados ante estas novas tecnologias e práticas de mercado.

O objetivo desta pesquisa é avaliar a importância da transparência fiscal se tornar uma política pública internacional. A expansão dos negócios transfronteiriços oferecem maiores chances de evasão fiscal, planejamento tributário lícito e ilícito, em prejuízo das finanças públicas dos Estados nacionais, sobretudo, das nações em desenvolvimento. $\mathrm{O}$ ritmo da globalização impõe novos padrões de eficiência econômica, de relações comerciais e tributárias. A globalização não tem facilitado a correção das nefastas favelizações e misérias sociais, em ofensa aos direitos humanos. Entre as características desta nova realidade, virtual, tem-se a intangibilidade, as transações territoriais e extraterritoriais, a romperem com os paradigmas e modelos de regulação tributária calcados em concepções de soberania, bens materiais, espaço e tempo. O Estado não pode ficar à margem nesta Era de Informações online.

Neste contexto, esta pesquisa qualitativa busca reunir informações existentes $n$ acervo bibliográfico nacional e internacional, de forma a aclarar e conduzir esta investigação. Assim, este estudo adota como hipótese de trabalho, que a necessidade de transparência fiscal no Mundo necessita ser implementada, com máxima urgência, para acabar com os paraísos fiscais e desobstruir um novo ciclo de desenvolvimento real; o quadro se agrava, sobretudo, após a Covid-19, pois as finanças públicas das nações em desenvolvimento ficaram abaladas. 
Muitas medidas já vêm sendo desenvolvidas neste sentido. As nações celebram instrumentos internacionais para troca de informações fiscais, para manterem hígidas, o quanto possível suas bases tributárias. Atualmente são três estes instrumentos: a) as Convenções tributárias bilaterais, nos moldes das Convenções Modelos da OCDE e ONU, para evitar dupla tributação e evasões fiscais, que servem de parâmetro para as negociações entre dois países e, nos termos do art. 26, das respectivas convenções, que orientam sobre a troca de informações fiscais; b) Acordo para trocas de informações tributárias (TIEAs) foi desenvolvido por um Grupo de Trabalho no âmbito da OCDE, para obtenção de informações fiscais em "paraísos fiscais" quando não conveniente, com estes, acordos bilaterais contra bitributação e; c) Convenção Multilateral sobre Assistência Administrativa em Matéria Tributária gestada no âmbito da OCDE, em que as negociações se arrastam desde 2010/2011 e que o Brasil ratificou em 2016, para transferências automáticas de informações sobre impostos federais.

Desta forma, no primeiro capítulo serão examinados os desafios tributários diante do comércio eletrônico. No segundo capítulo, observar-se-á, as limitações dos velhos tratados internacionais contra bitributação e examina o princípio da tributação da renda universal. Por fim, no terceiro capítulo será examinada a importância da cooperação internacional para troca automática de informações fiscais, para a proteção da saúde das finanças públicas das nações, sobretudo, em desenvolvimento, para evitar a corrosão das bases tributárias das nações. Investigar direito e tecnologia vem se transformando em uma nova fronteira de pesquisa, mas o percurso será longo a atrair novas pesquisas.

\section{DESAFIOS TRIBUTÁRIOS DO COMÉRCIO ELETRÔNICO}

Uma nova onda de globalização expandiu-se graças às tecnologias cibernéticas pela Internet. Assim, o e-commerce se expande na rede mundial de computadores unindo usuários e fornecedores em larga escala. Inúmeras transações financeiras opacas são desencadeadas diariamente via Internet. Assim, o presente artigo toma como premissa nuclear, que atualmente se faz indispensável para a preservação da base tributária das nações a transparência nas trocas de informações fiscais internacionais e nacionais acabar com os paraísos fiscais pode ser a saída para um novo ciclo de desenvolvimento global (OECD, 2019).

Serviços de informação online operam sistemas Bulletin board system (BBS) ou Electronic Data Interchange (EDI) cada dia mais sofisticados; novas nomeclaturas, 
ferramentas, termos técnicos, linguagens de programas proliferam-se na economia eletrônica global: chats (canais de diálogos); telnet (acesso remoto); IP (protoloco na internet); MP3 (ou MPEG Audio Layer-3 tem um formato de arquivo que permite ouvir músicas no computador com ótima qualidade); desenvolvimento de produtos por $3 D$ printing, media content, gopher (progama integrador de plataformas diferentes); utilização de tecnologias como IaaS - Infrastructure as a Service, para armazenar e acessar dados em um provedor "nas nuvens", cloud comuting (computação na nuvem, para guarda de arquivos, a liberar espaços físicos) e, PaaS-Plataform as a Service, dispondo via Internet plataformas para desenvolvimento de softwares), comércio eletrônico B2C (Business to Consumer) e B2B (Business to Business), para compra e venda de bens e serviços intangíveis e físicos, entre outras derivações destes tipos de negócios eletrônicos; UBER, videoconferências; e-Learning; frameworks para $e$ commerce, superando as noções físicas tradicionais, com características transnacionais (BOMTEMPO, 2016, p. 57). São diversas as modalidades de $e$-commerce, inclusive, B2A (Business to Administration) e o C2A (Consumer to Administration) tendem à expansão (BIFANO, 2004, p. 136).

Projeções realizadas no ano 2001, no âmbito da Universidade de São Paulo projetavam que em 2004, cerca de $25 \%$ das compras já poderiam ser realizadas pela Internet (WRIGHT; GIOVINAZZO; REIS, 2001). Estudos também demonstram preocupação com o varejo de pequenas cidades (DANTAS, 2019). O volume de vendas por e-commerce no Brasil em 2020 chega à ordem de R $\$ 106$ bilhões (ASSOCIAÇÃO BRASILEIRA DE COMÉRCIO ELETRÔNICO, 2020). Segundo Scherkekewitz, o Brasil já é o quinto país do mundo com mais acessos à Internet; em 2013, cerca de $60 \%$ dos domicílios brasileiros tinham acesso à Internet. O Brasil perde, em quantidade de pontos de acesso, somente para a China, os Estados Unidos, a Índia e o Japão (SCHERKEKEWITZ, 2014, p. 19-29). Por outro lado, um dado interessante: o comércio eletrônico vinha crescendo progressivamente 19,4\% ao ano em 2011 (E-COMMERCE BR, 2011).

O volume de dados circulando na internet preocupa. Recentemente, o Brasil, editou a Lei 12.965, 23 de abril de 2014, para disciplinar o marco civil da Internet, indispensável ao desenvolvimento com segurança jurídica. No entanto, os recursos de sistemas com inteligência artificial são bem invasivos à privacidade e segurança das pessoas, empresas e instituições, razão da edição da Lei Geral de Proteção de Dados. 
Por outro lado, a Comissão da União Européia, também, comenta sobre algumas características marcantes da economia digital, quais sejam, permite um nível de mobilidade sem precedentes, onde bens intangíveis, por vezes, se tornam mais importantes que bens físicos, a menores custos marginais de produção, ou seja, vai reduzindo a cada produção o custo de cada produto adicional; o rompimento de barreiras geográficas permite maiores ganhos a menores custos, satisfazendo mais o cliente individual e, ainda, permite otimizar as cadeias de valor na produção de bens e serviços (EUROPEAN COMISSION, 2014). Com os serviços de cloud computing (armazenamento de dados nas nuvens), a eficiência dos custos deve aumentar. Este serviço elimina uma série de arquivos de documentos, espaços físicos, depósitos, o que representa significativa economia para empresas, serviços públicos, tribunais, entre outros. As tecnologias como IaaS - Infrastructure as a Service (o usuário pode acessar dados em um provedor "nas nuvens") e, também, PaaS - Plataform as a Service (disponibilizar pela Internet plataformas para desenvolvimento de softwares) favorecem a produtividade (NUBLING, 2011). Outras tecnologias vêm sendo desenvolvidas, sobretudo, para internet das coisas.

O público jovem solteiro, principalmente, tem acessado mais a Internet pelos aparelhos móveis: $96 \%$ em casa; $87 \%$ no trabalho e $83 \%$ no restaurante (GOOGLE, 2021). Os usuários de e-books revelou que os jovens entre 18 a 29 anos, cerca de $21 \%$ da classe "A", detentores de cursos superiores, são os principais leitores de e-books no Brasil (NUNES, 2012). Rayport e Sviokla explicam que o no mundo virtual, os empreendedores exploram o marketplace (as disponibilidades de informações novas), o que amplia oportunidades de negócios rentáveis (RAYPORT; SVIOKLA, 1995). A tecnologia ultrarrápida (5G) abre enormes oportunidades de negócios, mas, estudos estão sendo desenvolvidos questionando eventuais efeitos nocivos destes campos magnéticos sobre insetos e a saúde dos seres humanos (INSTITUTO HUMANITAS UNISINOS, 2021).

Neste cenário, o esforço para evitar a erosão das bases tributárias tem sido considerável. No direito tributário internacional os modelos impositivos fundamentais observam ou a fonte ou residência. Isto é, ou se observa o princípio da fonte (sourcebased taxation principle), ou o princípio da residência (para a tributação sobre a renda universal: worldwide income principle). A tributação sobre a renda universal é mais ampla, pois na tributação pelo Estado da Fonte se limita ao "Estado de proveniência dos 
rendimentos" (MOREIRA JÚNIOR, 2003, p. 198). Nem sempre operações transfronteiriças se convertem em tributação para o Estado da Fonte.

Porém, se a tributação se dá pelo Estado da Residência (com base no domicílio fiscal), pelo princípio da renda universal, seja onde for gerada a renda será tributada; no Brasil este critério foi adotado a partir da edição da Lei 9.249, de 1995, e depois, com o advento da Lei 7.713, de 1988. Mesmo com as dificuldades de informações fiscais o modelo de tributação pela renda universal se mostra mais adequado para se chegar o responsável tributário na cadeia geradora da renda (personal fiscal attachments), a permitir, inclusive, verificação de eventual operação denominada treaty shopping (para redução ou eliminação de tributo, via planejamento tributário). Descobrir determinadas manobras evasivas se tornou tarefa árdua na economia eletrônica, com milhares de transações online, a exigir capacidade tecnológica fiscal crescente. Por isso, na Europa, tomando por base a cláusula de não tributação da Convenção Modelo da OECD e as bases do direito comunitário, as regras de fixação de estabelecimento fiscal, de abertura de filiais são mais restritivas e rígidas, para evitar a elusão fiscal e a competição tributária nociva, em prejuízo da harmonia no mercado comum (NOVOA; TORRES, 2008, p. 657). A elisão fiscal trabalha com as normas imponíveis para colocar o fato gerador em locais cujo sistema tributário seja mais favorecido (MOREIRA JÚNIOR, 2003, p. 221). Inclusive, autoridades norte-americanas também investigam operações suspeitas de lavagem de dinheiro por instituições financeiras envolvendo trilhões de dólares em transações internacionais (HUDSON, 2021).

São U\$ 253 trilhões de dólares de estoque de dívidas no planeta Terra alimentando a especulação financeira. Segundo a BBC News a relação dívida pública / PIB das nações segue da seguinte forma: China 310\%, Japão, 226,3\%; Estados Unidos, 101\%; zona do Euro, $100 \%$ e o Brasil, 87,9\% do PIB (BBC NEWS, 2020). Em cenário de pandemia a arrecadação cai, logo, o estoque de dívida pode descompensar os governos (WORLD BANK GROUP, 2020, p. 45). As transações realizadas entre empresas transnacionais no mercado mundial alcançam proporções significativas e crescentes, o que lhes permite redução de custos, aumento de lucros e sensível redução na carga tributária de diversos governos ao mesmo tempo. Para reverter esta dificuldade no mapeamento dos lucros de grandes empresas, sobretudo, algumas medidas vêm sendo empreendidas: a) busca de transparência fiscal; b) tem sido empreendidos mais controles nas regras de CFC; c) monitoramento das bases tributárias (BEPS); d) os tratados contra dupla tributação estão 
sendo mais cautelosos e restritivos; e) observância de estabelecimentos permanentes; f) maior fiscalização em abatimentos de juros nas apurações de lucros; g) atenção a preços de transferência; g) busca de soluções de conflitos fiscais" (OECD, 2013).

No âmbito da OECD resolveu estudar questionamentos diversos surgiram quanto à aplicação do VAT - Value-Added Tax (conhecido no Brasil e Portugal como Imposto sobre o Valor Agregado), razão de a União Europeia ter nomeado uma Comissão para fazer estudos para melhor tributar as operações eletrônicas. Inclusive, estudos no seio da Receita Federal do Brasil tem adotado o conceito de serviço técnico na utilização de estruturas tecnológicas para o exame da tributação pertinente - Instrução Normativa n. 1.455 , de 2014.

Nos Estados Unidos, segundo Radin, Rothchild e Silverman reconhecem que "a utilização da Internet para facilitar a venda faz aumentar o prejuízo fiscal para os governos estaduais e locais" (RADIN; ROTHCHILD; SILVERMAN, 2002, p. 1.143). O comércio eletrônico facilita muito a mobilidade de capitais nas transações (PIRES, 2011, p. 527). Por isso, o comércio eletrônico tem atraído muitos estudos na OECD. Neste sentido, o Plano de Ação da OECD, de 2013, foi reexaminado, em 2015 (Addressing the Tax Challenges of the Digital Economy, Action 1, 2015), cujo relatório final observou algumas providências necessárias, quanto ao e-commerce: a) evitar que governos encontrem dificuldades no cenário de fragmentação dos negócios; b) em razão do $e$ commerce (B2C) deve ser considerado o estabelecimento estável para efeito de recolhimento do imposto; c) dar mais atenção aos preços de transferências devido a assimetrias informacionais; d) tributar os ganhos na da empresa mãe; e) sejam acompanhados os desafios tributários de bens intangíveis sobre o valor agregado (IVA) substituindo tratados bilaterais por multilaterais na OECD na tributação sobre o consumo; f) haverá aumento de intangíveis e de sua dependência nas relações; g) uso de dados de consumidores aumentará, juntamente com a dificuldade de identificar a jurisdição e o estabelecimento fiscal. A tributação do VAT no destino se mostra mais neutra ao sistema produtivo (OECD, 2015, passim). André Portella registra que os estados e municípios brasileiros terão enormes dificuldades para controlar a imponibilidade tributária no cenário do comércio eletrônico, por falta de infraestrutura, sistemas atualizados de informações, sendo que o controle do ICMS e ISS gerarão maiores dificuldades (PORTELA, 2007, p. 68). 
Inclusive, após a aprovação da PEC 197/2012, que deu origem a Emenda Constitucional 87/2015 no Brasil, sob a influência do e-commerce, foi revista a tributação do ICMS, para beneficiar também o destino, com regras de transição. Não é objeto de este artigo abordar os detalhes desta alteração legislativa, mas, em linhas gerais, a diferença entre a alíquota interna do Estado vendedor e a alíquota interestadual para o Estado destinatário deverá ser partilhada entre os estados na proporção contida na regra do convênio celebrado via CONFAZ - Conselho Nacional de Política Fazendária. No Brasil se uma empresa venda para um consumidor final (não contribuinte), a própria empresa recolhe a DIFAL (diferença de alíquota do ICMS). São várias situações.

Em Portugal, Gloria Teixeira registra que em termos de IVA na União Europeia, o adquirente (consumidor particular), em geral, não é o sujeito passivo. A tributação será direcionada para a sede da empresa, ou seu estabelecimento estável, pode ainda, ser direcionada a cobrança para o domicílio do prestador de serviços: um exemplo se tem no sujeito passivo português que presta serviços para um consumidor particular na França, o VAT será recolhido no local da prestação de serviços: no caso, Portugal (TEIXEIRA; RODIGUEZ, 2014). No entanto, a solução não é simples diante da expansão da economia digital. Afonso e Porto revelam estudos realizados pela Digital Tax Index, em 2017, a revelar que a taxa efetiva por pessoa jurídica na tributação internacional tradicional é de $23,2 \%$ no B2C digital é $10,1 \%$ e no B2B 8,9\%, o que revela uma potencialidade disruptiva (AFONSO; PORTO, AFONSO; SANTANA, 2014, p. 94).

O problema tributário ficou mais grave com a pandemia da Covid-19. Estima-se que no mínimo 5\% do PIB - Produto Interno Bruto das nações se revertam para recuperações econômicas. Na zona do Euro as ações têm sido rápidas e com valores expressivos, para evitar efeitos em cascata e também efeitos políticos, econômicos e sociais, em razão desta pandemia do Coronavírus (INFOLIBRE, 2020). Fere a dignidade das pessoas e seus direitos humanos a expansão de favelas e exclusões sociais. Inclusive, nos Estados Unidos, a Senadora Bernier Sanders representando 68 organizações sociais encaminhou um "Projeto de Lei da Prosperidade Inclusiva, em 2019" (UNITED STATE CONGRESS, 2019), para taxar os rendimentos dos capitais especulativos. A Covid-19 demonstrou as fragilidades norte-americanas, com 27 milhões de pessoas sem seguro saúde e sem trabalho.

No sentido de reduzir a sonegação fiscal, como sugere Pinheiro, deveria ser aplicada uma alíquota diferenciada para transações virtuais por segmentos. Além disso, 
para evitar a sonegação, segundo Pinheiro, tem-se a conscientização do consumidor, que deve exigir notas fiscais, associar tais operações à aquisição de seguros (PINHEIRO, 2013, p. 269-271). Por isso, no Brasil, as administrações tributárias estão se utilizando de softwares específicos, para rastrear informações fiscais, via SINTEGRA e convênios.

\section{LIMITAÇÕES DOS TRATADOS INTERNACIONAL CONTRA BITRIBUTAÇÃO}

As nações civilizadas, em geral, têm empreendido muitos esforços voluntários, legislativos e operacionais, em busca de conferir efetividade ao princípio da neutralidade tributária no comércio internacional, para gravar minimamente possível as transações, para evitar a dupla tributação internacional, inclusive, prevendo troca de informações fiscais, para evitar a corrosão da base tributária, sobretudo, ameaçada por diversas manobras lesivas aos erários, bem como, pela transnacionalidade do comércio eletrônico (ANDRADE, 2008, p. 154).

Consta no Relatório da Comissão de Experts da União Européia alguns princípios orientam a tributação internacional: a) neutralidade, ou seja, inexistência de discriminação fiscal; b) eficiência, ou seja, minimização dos custos na cobrança dos impostos; d) certeza e simplicidade, para melhor compreensão dos contribuintes e para não diferenciar a tributação do comércio eletrônico do comércio convencional; e) efetividade, equidade e flexibilidade na tributação do comércio eletrônico (EUROPEAN COMISSION, 2014).

Sabe-se que as legislações internas das Nações, em geral, contêm medidas unilaterais para reduzir a dupla tributação internacional, para viabilizar o intercâmbio de pessoas e negócios no comércio exterior. Entre os métodos unilaterais para evitar a dupla, ou plúrima, tributação, por exemplo, são evidenciados nas relações internacionais: a) método da isenção tributária; b) crédito do imposto; c) dedução de tributos pagos no exterior como despesa; d) crédito do imposto societário, entre outros.

Observa-se, que o método da isenção se expressa como critério da neutralidade fiscal à importação, para evitar que a entrada de capitais produzidos no exterior sofram medidas protecionistas de cunho extrafiscal, com base no princípio da igualdade, entre residentes e não residentes, em busca de paridade de tratamento e concorrência entre os investidores externos e os internos (ultranational individual equity principle). O método da isenção comporta a modalidade da isenção integral (full exemption) e, também, da 
isenção com progressividade (excemption with progression). Neste particular, a Convenção Modelo da OECD prevê no art. 23, prevê o Método da Isenção como forma de se evitar a bitributação internacional. Como bem demonstra Heleno Torres, a isenção exclui internamente da tributação os fatos formadores de renda com elementos de estraneidade produzidos fora do território do Estado tributante (TORRES, 2001, p. 431). Mesmo na modalidade da isenção com progressividade, embora não compute na base de cálculo o rendimento obtido no exterior, mas considerando-a, faz-se uma tributação progressiva internamente (BORGES; KHOURI, 2008, p. 2533), nem sempre é fácil aprovar uma progressividade no regime democrático. Pela modalidade da isenção integral (full exemption), o Estado não tributa os elementos redituais de fonte estrangeira fazendo a exclusão destes da base de cálculo dos impostos internos. O Estado da fonte geralmente perde arrecadação, pois a isenção tem natureza de privilégio fiscal infraconstitucional.

O manual para negociações bilaterais contra dupla tributação elaborado pela ONU se dedica a dar apoio aos países emergentes. Revela que as medidas unilaterais de isenção contra a bitributação internacional são insuficientes para resolver a questão (UNITED NATIONS, 2019). Assim, visando encontrar meios para equacionar situações indesejáveis causados pela pluritributação internacional, a sobrecarregar, por vezes, os agentes econômicos, injustamente, os Estados adotam o princípio da tributação sobre a renda universal como visto acima, e neste caso, não se foca mais a tributação somente pela via da primazia do princípio da territorialidade, pois esta está absorvida pelo princípio da universalidade.

A regra matriz da Convenção Modelo da OECD oferece parâmetros internacionais, para evitar a dupla tributação sobre a renda e o patrimônio de pessoas e agentes econômicos. Esta Convenção Modelo da OECD (CMOECD) inicia-se fazendo a conceituação de residente e estabelecimento estável nos artigos $4^{\circ}$ e $5^{\circ}$, para depois se deter sobre a tributação de cada tipo de rendimento: sobre bens imobiliários, lucros, navegação marítima, controle societário por empresa associada, dividendos, juros, entre outros, dos capítulos $6^{\circ}$ a 22 , para depois examinar os métodos de isenção e imputação para eliminação da dupla tributação internacional, a partir do artigo 23. Prevê cláusula de troca de informações fiscais no artigo 26. Como forma de se evitar a dupla tributação sobre a renda, pode-se observar o item 3, do art. 23, do Acordo Contra Dupla Tributação Internacional Brasil - Itália, aplicando o método da isenção, conforme o Decreto 85.985, de 6 de maio de 1971: “3. Quando uma sociedade residente da Itália detiver pelo menos 
$25 \%$ (...) do capital de uma sociedade residente no Brasil, a Itália isentará de imposto os dividendos recebidos pela residente da Itália da sociedade residente do Brasil" (OECD, 2005).

De toda sorte, a influência desta economia eletrônica no dia-a-dia fiscal já se observa no Brasil que vem reagindo diante da crescente economia digital fazendo um esforço para expandir a tributação pelas vias informáticas, com a criação do SPED Sistema Público de Escrituração Digital, nota fiscal eletrônica, e-Social, entre tantos engenhos eletrônicos. Isso facilita o cruzamento de dados fiscais, e também, havendo uma tributação sobre movimentações financeiras pode se tornar viável ter estabelecimentos comerciais virtuais mediante chaves eletrônicas. Contudo, atualmente, não será “estabelecimento estável”, se determinada empresa atuar, por exemplo, por escritório com corretor credenciado no país contratante (CMOECD, art. 5\%, inciso 6). Entende-se, neste caso, por estabelecimento estável, um local de direção, uma oficina, uma sucursal, uma fábrica, um escritório, mina, entre outras possibilidades, a demonstrar que este conceito, no âmbito da OECD tem amplitude. Na prática, pode-se observar que uma representação empresarial pode estar vinculada a uma ou mais pessoas coletivas, a exigir cautelas. Historicamente, porém, no Brasil, a legislação exige presença "demorada" do estabelecimento permanente, bem como, o registro de domicílio fiscal era obrigatório (LINB, artigo 11; Lei 6.404/76, artigo 64; CTN, artigo 126, inciso III). O Novo Código Civil admite que funcione estabelecimento permanente por simples autorização do Poder Executivo, conforme os artigos 1134 e 1123, do Código Civil (TORRES, 2001, p. 201249). No entanto, as normas de direito público prevalecem. Tavolaro considera que um estabelecimento permanente se caracteriza quando ocorre uma atividade empresarial formalizada e efetiva em outro país" (TAVOLARO, 2021).

Por outro lado, a Itália adotou o sistema da imputação, para reduzir a dupla tributação internacional e para concessão de créditos de impostos de rendas produzidas no exterior, em sua proporção em relação à renda formada internamente. Neste caso, Torres demonstra como pode ser apurado o imposto: Exemplo: renda italiana: 80; renda estrangeira: 20; logo, rendimento worldwide $=100$. Incide $36 \%$ sobre os $100=36$. Assim, 36 x 20/100 = 7,2. Este é o valor do crédito tributário na Itália (TORRES, 2001, p. 489). No entanto, Maria Castelon faz o registro de que o Brasil tem um terço de seus acordos contra bitributação assinados pelo método da isenção (CASTELO, CASTRO; CASTRO. 2010, P. 136-141). Torres, porém, comenta que este método dedutivo do imposto sobre a 
base de cálculo, geralmente, tem aplicação "subsidiária", sobretudo, se tipologia de impostos interna difere do sistema de impostos do país estrangeiro, ou se houver um excedente de crédito de imposto, a minorar os efeitos da tributação, enquanto meio para tentar alcançar certa eficiência tributária, como meio termo entre o método da isenção e o método do crédito do imposto (TORRES, 2001, p. 471).

Há, também, a possibilidade de se fazer a compensação do crédito do imposto pago no exterior em relação ao imposto a ser pago internamente, pelo método do crédito do imposto (tax credit), o que não dependerá de nenhuma discricionariedade, desde que o imposto recolhido seja sobre o mesmo rendimento, observada a literalidade dos requisitos objetivos fixados por lei, para que tal crédito seja deferido, a menos que haja cláusula em possível tratado contra dupla tributação internacional (norma especial) a incidir sobre a questão. Cabe registrar, ainda, que o tax credit se mostra peculiar à tributação sobre a renda universal, mas tanto pode ser estabelecido por convenção internacional contra dupla tributação, como por legislação interna.

Segundo Torres, também, este método possui duas modalidades: o crédito de imposto integral e o crédito de imposto ordinário. Pelo crédito do imposto integral, se o imposto forâneo for pago a maior, o Estado deve compensar de alguma forma este crédito, observado o princípio da igualdade entre residentes e não residentes. Já no crédito do imposto ordinário, o crédito do imposto pago no exterior se vê imputável até o limite de tributação no Estado da residência, segundo Torres, a desconsiderar qualquer imposto a maior no exterior, observadas as limitações da legislação do país à concessão do crédito (TORRES, 2001, p. 444). Segundo Eveline Brígido, apesar deste tipo de método poder ser regulado por legislação interna, mostra-se comum que países desenvolvidos imponham cláusulas tax sparing e matching credit, em seus acordos contra bitributação internacional, como uma forma de incentivo fiscal, para atrair investimentos externos (BRÍGIDO, 2012). Heleno Torres alerta, todavia, que estas cláusulas de tax sparing e matching credit, por vezes, podem constituir formas fomentadoras de "concorrência fiscal prejudicial" (TORRES, 2001, p. 468). O problema é se os fiscos não alcançarem as informações corretas e ainda derem créditos.

Vito Thuronyi explica que uma rede de tratados contra bitributação pode constituir riscos de se criar uma "rede inflexível" de tratados, enquanto as mudanças econômicas da globalização são consideravelmente dinâmicas, sendo impossível alterar os tratados bilaterais em tempo hábil. Por isso, sugere que sejam realizados esforços no 
sentido de criar tratados multilaterais em matéria tributária, mais flexíveis, com mecanismos para a revisão e alteração de suas cláusulas, e mesmo, com a criação de uma organização internacional de cooperação em matéria tributária (THURONYI, 2001).

\section{A IMPORTÂNCIA DA COOPERAÇÃO PARA TROCA DE INFORMAÇÕES FISCAIS: O CERCO AOS PARAÍSOS FISCAIS}

A competição tributária internacional nociva vem sendo combatida nas últimas duas décadas graças a estudos avançados no seio da OECD e da Organização Mundial do Comércio. Os acordos contra dupla tributação internacional passaram a versarem sobre a troca de informações como forma de prevenir a evasão fiscal, mas revelam-se insuficientes diante da globalização tecnológica. A formação de blocos econômicos, de livre comércio, para evitar a discriminação tributária tem possibilitado vitórias rumo à efetividade do princípio da neutralidade fiscal normativa.

$O$ Brasil tem avançado muito em matéria de direito tributário internacional. Heleno Torres demonstra que o Brasil vem aderindo a um modelo de "tributação global" sofisticado, para evitar a evasão no pagamento de impostos (TORRES, 2015). Cerca de 128 países estabeleceram um Fórum Global, informal, para debater no seio da OECD evasões fiscais na globalização. O combate aos planejamentos tributários via "paraísos fiscais" foram objeto de estudos especializados (OECD - Harmful Tax Competition: an Emerging Global Issue, 1998), com novas investigações, sobretudo, em importantes negociações em 2011. Inicialmente buscou-se o aperfeiçoamento das legislações nacionais de controle de informações e, em seguida, a OECD estimulou um Modelo de negociações com "paraísos fiscais", sob a forma de Tax Information Exchange Agreement - TIEA (OECD, 2015), sem compromisso em relação a bitributação.

Em geral, os paraísos fiscais são utilizados para remessas e recebimentos de recursos no exterior, alcance de vantagem fiscal, lavagem de dinheiro e até para operações opacas. Atualmente novas tecnologias e moedas eletrônicas (criptomoedas) também fazem parte desta engrenagem fazendo surgir uma nova espécie: "paraíso fiscal digital"; as criptomoedas não permitem às autoridades fiscais acessarem as poupanças acumuladas, examinar a fonte da receita e tributá-la, o que favorece não somente o planejamento tributário, lícito e ilícito, como a lavagem de dinheiro (TEIXEIRA, SHCOUERI; FLÁVIO NETO; OLIVEIRA, 2020). 
Por outro lado, estudos e medidas no âmbito da OECD - G20 estão avançando em relação à obtenção de controle sobre as erosões de bases tributárias na economia digital (Base Erosion and Profit Shifting - BEPS), que tanto afetam os países em desenvolvimento. Em geral ocorrem por meio de estratégias lícitas e ilícitas de planejamento tributário, com o deslocamento de lucros para locais com tributação favorável, e também, por meio de pagamentos de juros, royalties, transferências de lucros, entre outras operações, com o objetivo de obtenção de vantagens competitivas no mercado global, o que vem afetar, sobretudo, a arrecadação do Imposto de Renda de Pessoas Jurídicas das nações menos desenvolvidas. O Grupo das 20 maiores economias mundiais têm empreendido esforços para que as empresas no mercado global empreendam trocas justas com responsabilidade e transparência fiscal. Estes esforços contam com uma plataforma de informações fiscais (Platform for Collaboration on Tax - PCT), que se vê alimentada por instituições internacionais como o FMI, OECD, G-20, Nações Unidas e Banco Mundial (OECD, 2013).

Neste ideal, também, com o objetivo de alcançar o controle multilateral da economia digital no conserto das nações, desde 2009 instaurou-se o Fórum Global no âmbito da OECD rompendo com a tradição do sigilo bancário, em busca de coerência, transparência e integridade nas operações digitais, com recomendações domésticas e internacionais. O Fórum Global para transparência fiscal já congrega em torno de 130 países, com mais de 500 delegados, o que vem possibilitando acesso a dados sobre 84 milhões de contas financeiras mantidas no exterior por residentes cobrindo ativos totais de EUR 10 trilhões. São francos progressos alcançados desde 2009 até 2019 (OECD, 2019). As criptomoedas não devem se tornar um retrocesso civilizatório.

Inclusive, para orientar a medição de riscos de prejuízos em preços de transferências (de lucros) foi editado um Manual que tem sido muito útil para obtenção de informações mais abrangentes de diversos países (OECD Handbook on Transfer Pricing Risk Assessment), o que pode complementar outras ferramentas de buscas por auditores fiscais em tempo razoável abastecendo o arquivo mestre, local e relatório por países, em operações transfronteiriças, monitorando transações de empresas transnacionais, observadas as cautelas quanto a segredos comerciais e sigilos fiscais (OECD, 2015).

Recentemente o Brasil aderiu ao Foreign Account Tax Compliance Act (FATCA), ratificou acordo para informações automáticas fiscais, bancárias e 
patrimoniais entre os Estados Unidos e o Brasil podendo ter acesso a dados disponíveis no sistema financeiro norte-americano. Ratificou a Convenção Multilateral sobre Assistência Mútua Administrativa em Matéria Fiscal. Nesta convenção multilateral muitos outros países membros estão aguardando a aprovação do Parlamento para ratificação. Convenção Automatic Exchange of Financial Information in Tax Matters (AEOI), ainda em tramitação no seio da Casa Civil do Governo brasileiro. O Brasil, no entanto, já atua em cooperação com o Programa BEPS - Base Erosion and Profit Shifting (OECD). Em 21 de julho de 2014, a OECD publicou a proposta de convenção Automatic Exchange of Financial Information in Tax Matters (AEOI) e visa adotar o padrão Common Reporting Standard, que guarda semelhanças com o FATCA (TORRES, 2015). A Convenção sobre Assistência Mútua Administrativa em Matéria Tributária emendada pelo Protocolo de $1^{\circ}$ de junho de 2010 , foi internalizado via promulgação do Decreto Federal n. 8.842, de 2016.

A Instrução Normativa n. 1.680, de 2016, orienta que as pessoas jurídicas são obrigadas a fazer a apresentação fiscal padrão, denominada "e-Financeira", que foi instituída em 2015, pela Instrução Normativa n. 1.571, de 2015, com a devida identificação de contas financeiras sob o rigor do Padrão de Declaração Comum (Common Reporting Standard - CRS) como deliberado por diversos países no âmbito da OECD, sobretudo, a vincular instituições financeiras e empresas de capital aberto, o que pode ser objeto de troca automática de informações. O advento do CRS melhora bem os controles, mas não significa o fim da evasão fiscal insternacional (offshore). A tendência nestes controles, mesmo a nível doméstico, a exemplo do Reino Unido, é que se faça um controle central de registros públicos sobre "proprietários beneficiários de empresas, fundos e fundações" (MEINZER, 2017).

O excesso de gastos e de endividamento público desestabilizaram as finanças da nação Italiana, e assim, o neoliberalismo se tornou o paradigma adotado (BAGIOLI, 2012). Ronald Paris fazendo referência aos estudos do economista Schumpeter, registra os perigos de uma deterioração da arrecadação tributária: poderia ter consequências políticas, não apenas econômicas (PARIS, 2013). As soluções passam pelo fortalecimento do Estado, via transparência fiscal, para que possa ter forças e agir como Estado-regulador. Jeffrey Owens, também, registra preocupações diante da economia eletrônica, pois os institutos tributários estão em boa parte limitados às fronteiras nacionais e a realidade mudou (OWENS, 2002). 
Carolina Machado fazendo referência à obra de Hermes Huck, assenta que a introdução desta cláusula legal de transparência fiscal na Convenção Modelo da OECD se fez motivada para evitar a utilização dos acordos internacionais contra bitributação para manobras de elisão e evasão fiscal internacional (MACHADO, 2021). Esta troca de informações entre fiscos tem previsão no artigo 26 da Convenção Modelo da OECD, em busca de alcançar reciprocidade. Todavia, o artigo 26 da Convenção Modelo da OECD permite que prevaleça o direito interno dos Estados, em face da polêmica questão do sigilo bancário. Nas Convenções Modelos da OCDE e da ONU nas respectivas cláusulas 26 permite trocas de informações fiscais. Entretanto, vom dificuldade editou-se no Brasil a Lei Complementar n. 105, de 2001, sem esvaziar o instituto constitucional do sigilo bancário. Segundo Prodanoff, com esta norma, preservou-se o "núcleo essencial” do sigilo bancário (PRODANOFF, 2008, p. 32), via autorização judicial. Desta forma, cresce o movimento internacional pela flexibilização do sigilo bancário. Alberto Xavier afirma que a comunidade internacional observa atenta um "futuro crepuscular" para os "paraísos fiscais", pois, os centros financeiros deverão se tornar transparentes (XAVIER, 2010, p. 671). Valadão também considera irreversível que os tratados internacionais insiram cláusulas de troca de informações fiscais (VALADÃO, 2009). Não se faz possível tanto otimismo, mas o processo de globalização reclama pela construção de consensos internacionais.

Neste ideal, como bem pontuam Godoy e Ribeiro, o "processo de internacionalização jurídica pelo qual o mundo passa amplia a necessidade e os rumos dos estudos de direito comparado" (GODOY; RIBEIRO, 2020). O direito informacional sabe que são quintilhões de bytes de dados trafegando na internet por dia, a impactar em vários aspectos jurídicos, sobretudo, na proteção dos dados sensíveis enquanto direitos humanos, razão da edição da Diretiva 95/45/CE do Parlamento Europeu, e em seguida, veio a lume o Regulamento Geral de Proteção de Dados (RGPD) da União Europeia 2016/679, que entrou em vigor em 2018, e na mesma trilha, veio a lume a Lei Geral de Proteção de Dados no Brasil. Inclusive, as manifestações ofensivas ao direto concorrencial e dos consumidores estão sendo combatidas na União Europeia (MASSEMO, 2019). O Estado também deve se proteger, a exemplo de esforços na Arábia Saudita sob influência do G-20 (OECD, 2020).

Tavolaro e Silva consideram que a troca de informações fiscais seja uma tendência irreversível no cenário mundial (TAVOLARO; ABREU E SILVA, 2021). O 
Brasil celebrou acordo internacional para troca de informações fiscais com os Estados Unidos, para combater questões relativas a crimes tributários (criminal tax matters). No âmbito da Comunidade Europeia tem-se o VIES - VAT Information Exchange System, para troca de informações (lotes fiscais) sobre consumo entre os países membros. No Brasil, o SINTEGRA - Sistema Integrado de Intercâmbio de Informações sobre o ICMS vem sendo alimentado pelos Estados brasileiros, desde 1997.

No entanto, com o desenvolvimento dos conhecimentos de informática, inteligência artificial, crescem também os crimes cibernéticos. Recentemente, a Receita Federal da Bulgária sofreu um ataque de um hacker que veio acessar dados de milhares de contribuintes (BOSTOCK, 2019). Logo, a transparência fiscal também pode facilitar o surgimento de crimes. A imprensa mundial vem noticiando ataques cibernéticos em várias nações, assim, os riscos de acesso ilícito a dados sigilosos ocorrem, a afetar a privacidade dos contribuintes (BROWN, SHOUERI; FLÁVIO NETO; OLIVEIRA, 2020). No entanto, não se pode pretender evolução ética sem trilhar pela ética. As Administrações Tributárias, em tese, têm o dever de assistência mútua mesmo a nível internacional (FERREIRA; LOYOLLA, 2002).

Contudo, segundo Nagel e Murphy o Estado é o garante de todos os direitos (NAGEL; MURPHY, 2005, p. 6). Ampliaram-se as possibilidades com a criação dos Sistemas taxXML e Worldtax (FERREIRA, 2001, p. 50), entre outros, ferramentas de inteligência artificial, que podem conduzir ao acesso a dados à margem da Lei de Proteção de Dados. O controle informacional é necessário; o distanciamento entre a evolução tecnológica e a ética tem consequências. Mas, a Receita Federal do Brasil está atenta. Na linha de manter a higidez da tributação. Em 2016 foi depositado pelo Brasil junto à OECD, o instrumento de ratificação da "Convenção Multilateral sobre Assistência Mútua Administrativa em Matéria Tributária", que entrou em vigor em $1^{\circ}$ de outubro de 2016, o que permite a troca de informações com mais 96 jurisdições que já assinaram esta Convenção Multilateral. O caminho da transparência fiscal vem ganhando força, coibindo a ocultação de ativos e lavagem de dinheiro (BRASIL, 2016).

No entanto, diante do interesse público das nações e a proteção de dados fiscais, prevalece o interesse público na LGPD brasileira e no RGPD da União Europeia. Bessa explica que o interesse público é o vetor preponderante, inclusive, cita a decisão do pedido cautelar na ADI 6.387 pelo Supremo Tribunal Federal analisando a constitucionalidade da Medida Provisória 954, de 2020, sobre a questão da produção de informações 
estatísticas em razão da Covid-19, pois não existe direito absoluto em matéria de proteção de dados sendo regulável legislativamente (BESSA, 2020). Desta forma, o melhor caminho será a utilização de novas formas tecnológicas para o alcance de evolução ética. A transparência fiscal pode favorecer ao desaparecimento de bolsões de misérias e conter a tendência das favelas triplicarem no mundo todo até 2050 (UNITED NATIONS, 2013).

\section{CONCLUSÕES}

A globalização, com a integração dos mercados online, instaura um processo revolucionário sem precedentes, em todas as nações ao mesmo tempo, com a ruptura de inúmeros paradigmas. $\mathrm{O}$ desenvolvimento do e-commerce revela a pujança dos negócios globais. Entretanto, inúmeras manobras ocorrem na competição tributária internacional, para evasão de pagamento de impostos, a projetar perigos políticos e econômicos se persistirem as corrosões de bases tributárias, em prejuízo, sobretudo, de nações mais pobres.

Restou confirmada a hipótese quanto ao ideal de fechar o cerco às manobras evasivas por paraísos fiscais. Há necessidade de transparência fiscal no Mundo, com máxima urgência, para abrir um novo ciclo de desenvolvimento real sustentável; há excesso de poupança estéril. Após a Covid-19 as finanças públicas das nações em desenvolvimento ficaram abaladas e, enquanto isso, o volume de recursos especulativos provoca misérias, o que se faz incompatível com os mais elevados ideais de direitos humanos e de justiça. Mais de 96 nações já aderiram à "Convenção sobre Assistência Mútua Administrativa em Matéria Tributária", de natureza multilateral internacional para troca de informações fiscais de iniciativa da OECD e os órgãos diplomáticos devem ampliar as adesões urgentemente fazendo um cerco às nubladas operações por paraísos fiscais.

Assim como se faz indispensável proteger os dados sensíveis das pessoas na economia informacional aberta, há também, que buscar a proteção de dados, das bases tributárias para a saúde das finanças públicas. Este estudo demonstrou que para a solução de tantos problemas sociais as administrações fiscais devem mover esforços pela higidez do sistema tributário, em observância ao princípio da tributação pela renda universal, com transparência fiscal, em defesa da democracia e sustentabilidade das políticas públicas. Após a Covid-19, o controle de operações por paraísos fiscais, via troca de informações fiscais pode reforçar a arrecadação dos Estados nacionais, o que desafia novas pesquisas 
tecnológicas para a gestão tributária, visando a sustentabilidade do Estado de Direito, das políticas públicas sociais e mantença das democracias.

\section{REFERÊNCIAS}

AFONSO, José Roberto; PORTO, Laís Khaled. Tributação sem Futuro. In: AFONSO, José Roberto; SANTANA, Hadassah Laís. Tributação 4.0. São Paulo: Almedina Brasil, 2020 .

ANDRADE, André. A Tributação Universal da Renda Empresarial. Belo Horizonte: Fórum, 2008.

ASSOCIAÇÃO BRASILEIRA DE COMÉRCIO ELETRÔNICO. Comércio eletrônico deve crescer $18 \%$ em 2020 e movimentar R \$ 106 bilhões. Disponível em: https://abcomm.org/noticias/comercio-eletronico-deve-crescer-18-em-2020-emovimentar-r-106-bilhoes/. Acesso em: 18 dez. 2021.

BAGIOLI, Frederico. Spending Review: Submissão dos Estados ao Princípio da Eficiência em Temos de Globalização. $1^{\circ}$ Curso de Introdução ao Direito Europeu: Tradizione Civilista e Armonizzazione Del Diritto nelle Corte Europee. Brasília: Publicações AGU, n. 21, set. 2012.

BBC News. Como o Brasil se compara com os países mais endividados do mundo. 15 fev. 2020. Disponível em: https://www.bbc.com/portuguese/internacional-51210538. Acesso em 15 dez. 2021.

BESSA, Leonardo Roescoe. A Lei Geral de Proteção de Dados e o Direito à Autodeterminação Informativa. Disponível em: https://www.conjur.com.br/2020-out26/leonardo-bessa-lgpd-direito-autodeterminacao-informativa. Acesso em: 18 nov. 2021.

BIFANO, Elidie. O Negócio Eletrônico e o Sistema Tributário Brasileiro. São Paulo: Quartier Latin, 2004.

BOMTEMPO, E.P.M. E-Commerce, Tributação e Cultura: Análise juseconômica das imunidades tributárias sobre as cadeias produtivas de livros e músicas. Curitiba: Juruá, 2016.

BORGES, Antonio Moura; KHOURY, Laila. A Troca de Informações no Âmbito de Tratados Internacionais sobre Matéria Tributária. In: XVII Congresso Nacional do CONPEDI. Anais, 2008, p. 2533. Disponível em: http://www.publicadireito.com.br/conpedi/manaus/arquivos/anais/brasilia/03_597.pdf.

Acesso em: 14 nov. 2021.

BOSTOCK, Bill. A hacker broke into Bulgaria's tax system and stole the details of every working adult in the country. Disponível em: https://www.businessinsider.com/hacker-steals-personal-data-every-taxpayer-bulgaria2019-7. Acesso em: 17 out. 2021. 
BRASIL. Receita Federal do Brasil. Brasil Ratifica a Convenção Multilateral e terá Amplo Acesso a Informações Tributárias do Exterior. Disponível em: https://receita.economia.gov.br/noticias/ascom/2016/junho/brasil-ratifica-a-convencaomultilateral-e-tera-amplo-acesso-a-informacoes-tributarias-do-exterior. Acesso em: 12 out. 2021.

BROWN, Patricia A. Some Recent Questions Regarding the Balance between Our Tax Obligations to Society and Individual Rights. In: SHOUERI, Luís Eduardo; FLÁVIO NETO, Luís; OLIVEIRA, Rodrigo Maito (Coord.). São Paulo: Anais. VIII - Congresso Brasileiro de Direito Internacional Tributário. Instituto Brasileiro de Direito Tributário, 2020.

BRIGIDO, Eveline. Bitributação Internacional da renda: as cláusulas de tax sparing e matching credit. Revista Amicus Curiae, Criciúma, v. 9, n. 9, 2012.

CASTELON, Marta Oliveiros. Caso EP Austríaco: Estado que isenta lucros deve deduzir prejuízos de estabelecimento permanente estrangeiro? In: CASTRO, Leonardo; CASTRO, Ailton et al. Tributação Internacional: análise de casos. São Paulo: MP Editora, 2010.

DANTAS, Rafael. O Futuro do Varejo e o Impacto do E-Commerce nas Cidades. Revista Algo Mais, Recife, 18 jul. 2019. Disponível em: http://revista.algomais.com/economia/ofuturo-do-varejo-e-o-impacto-do-e-commerce-nas-cidades. Acesso em: 19 nov. 2021.

E-COMMERCE BR. E-Commerce Deve Faturar US\$ 963 Bilhões no Mundo em 2013. E-Commerce News, São Paulo, 2011. Disponível em: https://www.ecommercebrasil.com.br/noticias/e-commerce-deve-faturar-mais-de-us963-bilhoes-em-2013/. Acesso em: 16 out. 2021.

EUROPEAN COMISSION. Report of the Commission Expert Group on Taxation of the Digital Economy. Bruxelas: Working Paper: Digital Economy - Facts \& Figures, 28 mai. 2014. Disponível em: https://ec.europa.eu/taxation_customs/sites/taxation/files/resources/documents/taxation/ gen_info/good_governance_matters/digital/2014-03-13_fact_figures.pdf. Acesso em: 20 nov. 2021.

FERREIRA, Antonio Sérgio Seco. Tecnologias de Suporte à Tributação do Comercio Eletrônico. Dissertação de Mestrado (2001). Universidade Católica de Brasília, Brasília, 2001.

FERREIRA, Antonio Sérgio Seco; LOYOLLA, Waldomiro. Tax XML - Sistema de Apoio à Cooperação Tributária Internacional. Revista de Administração de Empresas - RAE-eletrônica, Brasília, v. 1, n. 1, jan./jun. 2002. Disponível em: http://www.scielo.br/pdf/raeel/v1n1/v1n1a07.pdf. Acesso em: 17 nov. 2021.

GODOY, Arnaldo Sampaio de Moraes; RIBEIRO, Gustavo Ferreira. O direito comparado: Esforço de resgate historiográfico e de problemas metodológicos. Revista de Direito Internacional, Brasília, Uniceub, v. 17, n. 1, 2020. Disponível em: 
https://www.publicacoesacademicas.uniceub.br/rdi/article/view/6252. Acesso em: 15 nov. 2021.

GOOGLE. Informações Confidenciais e Reservadas Google. Nosso Planeta Móbile. Brasil. Disponível

em: https://services.google.com/fh/files/blogs/our_mobile_planet_brazil_pt_BR.pdf. Acesso em: 20 dez. 2021.

HUDSON, Michael. Dirty money has 'metastasized' within global banking system, top regulator says. Disponível em: https://www.icij.org/investigations/fincenfiles/dirty-money-has-metastasized-within-global-banking-system-top-regulator-says/.

Acesso em: 14. Out. 2021.

INFOLIBRE, 27 out. 2020. El Gobierno despliega el mayor gasto público de la Historia, hasta el 51,5\% del PIB, para hacer frente al covid-19. Disponível em: https://www.infolibre.es/noticias/economia/2020/05/02/el_gobierno_despliega_mayor_gasto_publico_ historia_hasta_del_pib_para_hacer_frente_covid_19_106417_1011.html. Acesso em: 17 Set. 2021.

INSTITUTO HUMANISTAS UNISINOS. Por que a Nova Tecnologia 5G Representa um Novo Perigo para a Vida? Disponível em: http://www.ihu.unisinos.br/78noticias/589826-por-que-a-tecnologia-5g-representa-um-novo-perigo-para-a-vida.

Acesso em: 19 dez. 2021.

MACHADO, Carolina. A Cooperação Tributária Internacional e o Estado Brasileiro.

Disponível

em:

http://www.publicadireito.com.br/conpedi/manaus/arquivos/anais/fortaleza/3083.pdf.

Acesso em: 14 dez. 2021.

MASSEMO, Manuel David. Como a União Europeia Procura Proteger os CidadãosConsumidores em Tempos de Big-Data. Revista Eletrônica do Curso de Direito da UFSM, Santa Maria, v. 14, n. 3, 2019. Disponível em: https://periodicos.ufsm.br/revistadireito/article/view/41708/pdf. Acesso em: 21 out. 2021.

MEINZER, Markus. Automatic Exchange of Information as the New Global Standard: The End of (Offshore Tax Evasion) History? 27 fev. 2017. Exposition: 2nd Turkish-German Biennial on International Tax Law in Istanbul Conference. Disponível em: https://ssrn.com/abstract=2924650. Acesso em: 10 Nov. 2021.

NUBLING, Gabriela. Cloud Computing Aplicada ao Cenário Corporativo. São Paulo: Faculdade de Tecnologia de São Paulo - TCC, 2011. Disponível em: http://www.fatecsp.br/dti/tcc/tcc0038.pdf. Acesso em: 11 Nov. 2021.

NOVOA, César García. Transparencia Fiscal Internacional y subcapitalización. In: TORRES, Heleno Traveira (Coord.). Direito Tributário Internacional. São Paulo: Quartier Latin, v. 8, 2008.

NUNES, Vivian. Livros Digitais: pesquisa revela o perfil dos consumidores destes dispositivos, 18 jun. 2012. Disponível em: http://www.infomoney.com.br/minhas- 
financas/gadgets/noticia/2469091/livros-digitais-estudo-revela-perfil-dos-consumidoresdesses-dispositivos. Acesso em: 16 Out. 2021.

OECD. Action Plan on Base Erosion and Profit Shifting. OCDE Publishing, 2013. Disponível em: http://dx.doi.org/10.1787/9789264202719-en. . Acesso em: 13 Nov. 2021.

OECD. Addressing the Tax Challenges of the Digital Economy, Action 1 - 2015. Final Report, OECD/G20 Base Erosion and Profit Shifting Project. Paris: OECD Publishing, 2015. Disponível em: https://www.oecd-ilibrary.org/taxation/oecd-g20-base-erosionand-profit-shifting-project_23132612. Acesso em: 12 Set. 2021.

OECD. Model Protocol for the Purpose of Allouwing the Automatic and Spontaneous Exchange of Information under a TIEA. 2015. Disponível em: https://www.oecd.org/ctp/exchange-of-tax-information/Model-Protocol-TIEA.pdf.

Acesso em: 14 Dez. 2021.

OECD. Model Tax Convention on Income and on Capital: Condensed Version 2005. Disponível em: https://doi.org/10.1787/mtc_cond-2005-en. Acesso em: 17 nov. 2021.

OECD. Global Forum on Transparency and Exchange of Information for Taxa Pusposes. Paris: OECD, 2019. Disponível em: http://www.oecd.org/tax/transparency/documents/global-forum-10-anniversaryflyer.pdf. Acesso em: 16 Nov. 2021.

OECD. OECD/G20 Inclusive Framework on BEPS Progress Report July 2018. May 2019. Disponível em: http://www.oecd.org/tax/beps/inclusive-framework-on-bepsprogress-report-july-2018-may-2019.pdf. Acesso em: 11 jan. 2021.

OECD. OECD Secretary-General Tax Report to G20 Finance Ministers adn Central Bank Governors. Saudi Arabia, jul. 2020. Disponível em: http://www.oecd.org/tax/oecd-secretary-general-tax-report-g20-finance-ministers-july2020.pdf. Acesso em: 14 Set. 2021.

OECD. Transfer Pricing Documentation and Country-by-Country Reporting, Action 13. 2015. Final Report. Paris: OECD Publishing, 2015. Disponível em: http://dx.doi.org/10.1787/9789264241480-en. Acesso em: 15 Set. 2021.

OWENS, Jeffrey. Taxation in a global environment. OECD Observer n. 230, Jan. 2002. Disponível em: https://oecdobserver.org/news/archivestory.php/aid/650/Taxation_in_a_global_environ ment.html. Acesso em: 22 Out. 2021.

PARIS, Roland. The Globalization of Taxation? Electronic Commerce and the Transformation of the State. University of Colorado. International Studies Quarterly, 2003. Disponível em: http://aix1.uottawa.ca/ rparis/global_taxation.pdf. Acesso em: 14 Set. 2021.

PINHEIRO, Juliana Peck. Direito Digital. 5ª ed. São Paulo: Ed. Saraiva, 2013. 
PIRES, Rita Calçada. Tributação Internacional do Rendimento Empresarial Gerado Através do Comércio Eletrônico: desvendar mitos e construir realidades. Coimbra: Almedina, 2011.

PORTELLA, André. Controle Tributário do Comércio Eletrônico. Belo Horizonte: Fórum, 2007.

PRODANOFF, Cristina. Sigilo Bancário. 2008. 47 f. Monografia de Conclusão (Especialização), Convênio UnB-Esaf, Rio de Janeiro, 2008.

RADIN, Margareth; ROTHCHILD, John; SILVERMAN, Gregory. Internet Commerce: The Emerging Legal Framework. New York: Foundation Press, 2002.

RAYPORT, Jeffrey; SVIOKLA, John. Exploiting the Virtual Value Chain. Harvard Business Review, v. 73, n. 6, nov./dez., 1995. Disponível em: https://hbr.org/1995/11/exploiting-the-virtual-value-chain. Acesso em: 13 Out. 2021.

SCHERKEKEWITZ, Iso Chaitz. Direito e Internet. São Paulo: Revista dos Tribunais, 2014.

TAVOLARO, Agostinho; ABREU E SILVA, Antonio Carlos. O Tratado de Troca de Informações Fiscais Brasil-Estados Unidos. Revista Brasileira de Comércio Exterior RBCE, Rio de Janeiro, n. 114, 2016. Disponível em: http://www.funcex.org.br/publicacoes/rbce/material/rbce/114_ATTACFAS. Acesso: 17 Jul. 2021.

TAVOLARO, Agostinho. O Estabelecimento Permanente: instituto próprio do direito tributário internacional. Disponível em: http://www.tavolaroadvogados.com/doutrina/cs495.pdf.

Acesso em: 17 Jul. 2021.

TEIXEIRA, Alexandre Alkmim. Paraísos Fiscais Digitais. In: SHOUERI, Luís Eduardo; FLÁVIO NETO, Luís; OLIVEIRA, Rodrigo Maito (Coord.). Anais. VIII - Congresso Brasileiro de Direito Internacional Tributário. São Paulo: Instituto Brasileiro de Direito Tributário, 2020.

TEIXEIRA, Glória; RODRIGUEZ, Abílio. Tributação do Comércio Eletrônico: Novos desafios. Boletim de Ciências Económicas, Coimbra, v. 57, n. 3, 2014. Disponível em: https://digitalis.uc.pt/ptpt/artigo/tributa\%C3\%A7\%C3\%A3o_do_com\%C3\%A9rcio_ele tr\%C3\%B3nico_novos_desafios. Acesso em: 16 Out. 2021.

THURONYI, Vito. International Tax Cooperation and a Multilateral Treaty. Brooklyn Jornal International Law, New York, n. 26, 1641, 2001. Disponível em: https://core.ac.uk/download/pdf/228609721.pdf. Acesso em: 12 Jul. 2021.

TORRES, Heleno Taveira. Brasil inova ao aderir às sofisticadas práticas do sistema do Fisco Global. Revista Consultor Jurídico, 8 jul. 2015. Disponível em: https://www.conjur.com.br/2015-jul-08/consultor-tributario-brasil-inova-aderir-praticassistema-fisco-global. Acesso em: 14 Nov. 2021. 
TORRES, Heleno. Pluritributação Internacional sobre as Rendas de Empresas. $2^{\text {a }}$ ed. São Paulo: Revista dos Tribunais, 2001.

UNITED NATIONS. Manual for Negotiation of Bilateral Tax Treaties Between Developed and Developing Countries. 2019. Disponível em: https://www.un.org/development/desa/financing/sites/www.un.org.development.desa.fi nancing/files/2020-03/manual-bilateral-tax-treaties-update-2019.pdf. Acesso em: 14 Set. 2021.

UNITED NATIONS. Sustainable development challenges. New York: Department of Economic and Social Affairs, World Economic and Social Survey 2013, 2013. Disponível em: https://www.un.org/en/development/desa/publications/world-economic-and-socialsurvey-2013-sustainable-development-challenges.html. Acesso em: 3 jan. 2021.

UNITED STATES CONGRESS. Cosponsor the Inclusive Prosperity Act of 2019. Disponível em: http://www.robinhoodtax.org/request-to-cosponsor-the-inclusiveprosperity-act-of-2019/

. Acesso em: 14 Set. 2021.

VALADÃO, Marcos Aurélio Pereira. Troca de Informações com Base em Tratados Internacionais: Uma necessidade e uma tendência irreversível. Revista de Direito Internacional Econômico e Tributário, Brasília, v. 4, n. 2, jul. /dez. 2009. Disponível em: https://portalrevistas.ucb.br/index.php/RDIET/article/view/4510/2819. Acesso em: 16 nov. 2021.

WORLD BANK GROUP. A Economia nos Tempos de Covid-19 (Versão Eletrônica), 2020, p. 45.4 Disponível https://www.worldbank.org/pt/country/brazil/publication/latin-america-brazil-economycoronavirus-pandemic-covid-19. Acesso em 19 Nov. 2021

WRIGHT, James; GIOVINAZZO, Renata; REIS, Cristina. Impacto do Comércio Eletrônico nos Negócios. Revista Administração, São Paulo, Fundação Escola de Comércio Álvares Penteado, v. 2, n. 2, abr./jun. 2001.

XAVIER, Alberto. Direito Tributário Internacional do Brasil. $7^{\text {a }}$ ed. Rio de Janeiro: Forense, 2010. 